$25 \%$ of their patients who present with musculoskeletal problems.

G M CHAMBERS

J W MYLES

M L SUTCLIFFE

D L JOHNS

Peterborough District Hospital,

Peterborough PE3 6DA

SIR,-I was one of the 65 women orthopaedic SHOs in 1984. I did the job as part of my GP scheme and found it the most enjoyable and possibly most useful of the hospital jobs I did. Considering how many patients with orthopaedic problems GPs see I have been surprised how few of them have done any orthopaedics. As with any specialty, an increase in the number of GPs with at least some basic knowledge should improve the standard of referrals.

There is always a shortage of obstetric SHO jobs as most GP trainees expect to do these. If more thought orthopaedics relevant perhaps more jobs could be filled by linking some jobs to GP schemes.

ANGela Salter

Gloucester

SIR,-It would seem that many senior house officer posts that are not at present filled could be filled by general practitioner trainees. This is precisely what has been done in the Salisbury Health District, with great success, over the past three years.

This has resulted in benefit to the young doctors concerned and to the general practitioners in the surrounding community, who have benefited from the widely disseminated knowledge that trainees have been able to take into their practice year. Given that many of these young doctors are likely to wish to settle as principals in the area it can only increase the pool of knowledge available within the general practitioner community and hence improve the overall standard of patient care. This in turn might reduce the load on the hard pressed departments of orthopaedics throughout the country by reducing the number of unneces sary referrals.

The heightened clinical awareness of young doctors in general practitioner training helps to provide a very high standard of medical care in the orthopaedic wards and also serves to update and disseminate medical knowledge to the consultants. Perhaps it would be opportune to review genera practitioner schemes in parts of the country where orthopaedic SHO posts are hard to fill and incorporate these posts within the training scheme.

J E Carvell

Department of Orthopaedics,

Odstock Hospital,

Salisbury SP2 7SX

\section{Ulcerogenicity of piroxicam}

SIR,-Dr Allen C Rossi and his colleagues (17 January, p 147) state that the higher rate of reporting with piroxicam does not prove that it has the greatest ulcerogenicity among these drugs, though they do not rule out the possibility. This praiseworthy caution is due to the reservations they express about the limitations of such a reporting method. What a pity they do not leave it at that. Instead, they discuss reports from Britain and surprisingly conclude, though not from their own work, that the ulcerogenicity of piroxicam prob- ably does not differ from that of other nonsteroidal anti-inflammatory drugs. The studies they cite are results of the yellow card ${ }^{1}$ and prescription event monitoring schemes, ${ }^{2}$ systems subject to many of the same limitations as their own.

Many doctors will worry that this paper will be misunderstood as finalising the question of gastrointestinal safety of piroxicam or even the non-steroidal anti-inflammatory drugs in general A decision last year by the Food and Drugs Administration not to ban the drug in the elderly and a recent leading article ${ }^{4}$ might be similarly misinterpreted. The difficulty of proving the ulcerogenicity of a drug has been well outlined. Case reports or studies that do not have the statistical power to incriminate a particular drug should not be used to ban a drug, but this does no mean that there is no further work to be done. A convincing association, almost certainly causal, has been shown between this group of drugs as whole and clinically important ulceration. ${ }^{67}$ Surely it is now time to evaluate the relative ulcerogenicity of individual drugs and risk-benefit ratios?

Prospective clinical trials have not yet been properly used for several reasons, including the considerable resources that would be needed. It has been estimated that 1600 patients would be needed in both treatment and control groups to detect a fivefold increase in ulcer development in patients taking an ulcerogenic drug. ${ }^{5}$ There is also a belief that everybody in such a trial would have to undergo endoscopy regularly. This would not be necessary as what is pertinent is symptomatic ulceration, perforation, or bleeding. Endoscopy would be indicated only when symptoms were present, though a high index of suspicion would be needed in elderly subjects, in whom pain is often absent. ${ }^{8}$ Similarly, providing a control group should not prove a problem. Non-steroidal antiinflammatory drugs are not life saving and it is feasible and ethical for patients with conditions such as osteoarthritis to take analgesics that are not suspected of causing ulcers.

A well mounted and independently conducted trial would serve as a "gold standard" for less arduous ways of assessing the ulcerogenicity of these drugs. Much of the recent public disquiet about the non-steroidal anti-inflammatory drugs has arisen because of the lack of scientific data with which to counter wilder media speculation. Spontaneous reports and more sophisticated versions such as prescription event monitoring may well play a major part in providing this. But they are likely to be widely accepted by clinicians only if they have been shown to correlate well with even one definitive trial of the gastrointestinal safety of a leading non-steroidal anti-inflammatory agent.

David Clinch

Southampton General Hospital,

Southampton $\mathrm{SO} 9 \mathrm{XY}$

1 Committee on Safety of Medicines. Non-steroidal anti-inflammatory drugs and serious gastrointestinal reactions. $\mathrm{Br}$ Med 1986;292:1190-1.

2 Anonymous. Comparative study of five NSAIDs. Drug Surveilance Research Unit Prescription-Event Monitoring News 1985; 3:3-13

3 US Food and Drug Administration. Center for Drugs and Biologics. Recommendation in piroxicam imminent hazard proceeding. Washington, DC: FDA, 1986 May 14.

4 Urquhart J. Two cheers for NSAIDs. Gut 1986;27:1287-91.

5 Kurata JH, Elashoff JD, Grossman MI. Inadequacy of the literature on the relationship between drugs, ulcers and gastrointestinal bleeding. Gastroenterology 1982;82:373-82.

6 Somerville K, Faulkner G, Langman M. Non-steroidal antiinflammatory drugs and bleeding peptic ulcer. Lancet 1986; 462-4.

7 Collier D St J, Pain JA. Perforation of peptic ulceration in the elderly. Gut 1985;26:1359-63.

8 Clinch D, Banerjee AK, Ostick G. Absence of abdominal pain in elderly patients with peptic ulcer. Age Ageing 1984;13:120-3.

\section{Self help groups}

SIR,-I am sure that Dr Stephen Lock is right when he suggests in his welcome article on self help groups (20-27 December, p 1599) that doctors on the whole do not know enough about them and, even when they do, often forget to tell patients about them. However, it will always be impossible for GPs to have detailed knowledge of more than a handful of their local groups: there are well over 100 in the Nottingham area. Perhaps we should therefore concentrate on telling our patients that the groups exist (and how they can be contacted) and leave it to them to decide whether or not they will benefit.

In practice it can be surprisingly difficult to get into the habit of telling patients about self help groups. There is a lot to be said for introducing doctors to self help groups at the undergraduate stage, and with the help of the Nottingham self help team and local groups we have been running seminars on this subject for the past three years. The self help team is a support, resource, and information centre for local self help groups and at each seminar for $16-20$ fourth year students provides speakers from the team and two local groups. Members of 16 self help groups have so far taken part, often giving moving accounts of their experiences and the way the group has helped them. As well as informing students about self help groups the seminars give them the opportunity to discuss their advantages and drawbacks and their relationships with professionals. Students have tended to come to the seminar with positive attitudes to self help groups and go away more positive: of the 96 who attended the seminar in 1986, 57 said that they would have considered informing patients about self help groups before the seminar, and 88 (92\%) said they would do so afterwards. We hope that the seminars will help them to remember self help groups better than those of us who were trained before the flowering of "the fourth estate in medicine."

JOHN TEMPLE

Department of General Practice

Queen's Medical Centre,

Nottingham NG7 2UH

SIR,-Dr Stephen Lock's article on self help groups deals with some aspects of the deficiency of patient information.

I propose that each health district should have not only a health education service about primary prevention but also an open access disease information service for patients and their families. This might have three functions.

Firstly, it could provide a drop in shop with pamphlets and books and a regularly updated computer catalogue of organisations and self help groups. Secondly, there should be regular group teaching sessions on specific illnesses, such as Parkinson's disease, dementia, "after the coronary," asthma, diabetes, AIDS, oesophagitis, irritable bowel, colitis, and breast cancer. These would be run by the best informed and best teacher available, who might be a nurse, stoma or speech therapist, self help group member, ex-patient, or doctor. Hospital doctors should have teaching sessions in their contracts. Thirdly, it would provide a focal point and back up service for self help groups.

Surveys show that many people cannot find the information they need. Doctors seem to be too busy and are often not the best teachers, despite their title. In these days of consumerism we should welcome the public's desire for accurate information given by someone who knows the subject in 